\title{
Uso de células mononucleares da medula óssea no tratamento de tendinites induzidas experimentalmente em equinos
}

\author{
[The use of mononuclear cells from bone marrow on the treatment of experimentally \\ induced tendinitis in horses] \\ P.G.G. Oliveira, A.L.G. Alves, A.M. Carvalho, C.A. Hussni, M.J. Watanabe, \\ R.L. Amorim, M.M.P. Rodrigues, L.S. Mota \\ Faculdade de Medicina Veterinária e Zootecnia - UNESP \\ Distrito de Rubião Júnior s/n \\ Caixa Postal 560 \\ 18618-000, Botucatu, SP \\ RESUMO
}

\begin{abstract}
Foram induzidas lesões no tendão flexor digital superficial (TFDS) de ambos os membros anteriores de seis equinos, seguidas de implante autólogo de células da fração mononuclear de medula óssea em apenas um membro de cada animal. Os animais foram avaliados por parâmetros clínicos, ultrassonográficos, histopatológico e imunoistoquímico. Paralelamente, realizou-se o cultivo de novas amostras para a caracterização das células utilizando-se marcadores CD34 e CD45 por meio da citometria de fluxo, confirmando a presença de células mesenquimais na fração mononuclear. A caracterização das fibras colágenas tipo I e tipo III no tecido neoformado mostrou melhora na qualidade da cicatrização tendínea dos membros tratados. A terapia com implante autólogo das células da fração mononuclear melhorou a organização tecidual e a sua qualidade, apresentando maior expressão significativa para colágeno tipo I.
\end{abstract}

Palavras-chave: equino, célula-tronco, fração mononuclear, medula óssea, tendão

\begin{abstract}
The present study was developed inducing a lesion in the SDFT of both thoracic limbs of six horses followed by autologous implantation of mononuclear cells from bone marrow in only one affected limb of each horse. The horses were evaluated through clinical and ultrasonography exams, and through histopathology and immunohistochemistry patterns. Concomitantly, new samples were cultivated and characterized using CD34 and CD45 markers, proving the presence of mesenchymal cells in the mononuclear fraction. The characterization of collagen fibers type I and type III in the new tissue has showed an improvement in tendon healing in treated limbs. The therapy with autologous implant of the mononuclear fraction has improved tissue organization and its quality, having a significanlyt higher expression of collagen type $I$.
\end{abstract}

Keywords: equine, stem cell, mononuclear fraction, bone marrow, tendon

\section{INTRODUÇÃO}

Lesões tendíneas e ligamentares afetando os tendões digitais (superficial e profundo) e o aparato suspensório são importantes causas de claudicação em cavalos atletas, resultando em queda de desempenho e possível afastamento do animal das pistas. Essas lesões se apresentam como ruptura parcial ou total das fibras tendíneas, geralmente afetando o tendão flexor digital superficial (TFDS) (Alves et al., 2001). Os quadros de tendinite possuem alta incidência e necessitam de um longo período de reabilitação. Os atuais tratamentos são de baixa eficácia na modulação do tecido cicatricial, ocorrendo variações em sua força e resistência,

Recebido em 9 de agosto de 2010

Aceito em 11 de agosto de 2011

E-mail: .patriciavet@terra.com.br 
resultando em uma função reduzida do novo tecido e predispondo-o a recidivas. A utilização da ultrassonografia para a avaliação de estruturas tendoligamentares permite melhor definição do diagnóstico, caracterizando o tipo da lesão e da estrutura afetada, sendo possível instituir um prognóstico mais adequado (Alves et al., 2001).

Estudos recentes vêm se concentrando no potencial terapêutico das células-tronco (CT), verificando sua possibilidade de aplicação em enfermidades complexas, ou em lesões de difícil cicatrização. As células-tronco mesenquimais possuem capacidade de autorreplicação, além da habilidade de se diferenciar em fibroblastos, osteoblastos, condrócitos, tenócitos, adipócitos e miofibroblastos, de acordo com o estímulo local (Fortier e Smith, 2008). Essa diferenciação ocorre por toda a vida, tornando seu estudo particularmente interessante em lesões do sistema musculoisquelético.

Dentre as células mononucleares estão presentes as células-tronco mesenquimais. $\mathrm{O}$ uso da fração mononuclear em tratamentos de lesões ortopédicas possui a vantagem de permitir a realização do implante no momento do diagnóstico, com menor tempo de preparo das células e custo reduzido, e ainda aumenta a concentração de células-tronco mesenquimais para o implante direto após a coleta de medula óssea quando comparado ao uso da medula óssea total (Barreira et al., 2008).

Este trabalho teve o objetivo de avaliar a qualidade da cicatrização tendínea nos membros tratados de equinos com implante de células mononucleares provenientes da medula óssea, por meio do acompanhamento clínico e ultrassonográfico, bem como avaliar as características morfológicas do tecido neoformado.

\section{MATERIAL E MÉTODOS}

A pesquisa foi aprovada pela Câmara de Ética em Experimentação Animal (número 18/2006). Foram utilizados seis equinos, distribuídos em dois grupos para formar seis membros em cada grupo e receber os tratamentos, após indução de tendinite pela aplicação de colagenase. Os animais, entre dois e três anos, quatro fêmeas e dois machos, da raça Árabe, foram mantidos em Hospital Veterinário Escola.
No dia zero do experimento, induziu-se a lesão no tendão flexor digital superficial (TFDS) de ambos os membros torácicos, por meio de injeção intratendínea de colagenase tipo I $(1 \mathrm{~mL}$; 2,5mg/mL - Sigma-Aldrich C-0130). Após a indução, os animais foram tratados com fenilbutazona $(2,2 \mathrm{mg} / \mathrm{kg})$, IV, uma vez ao dia durante sete dias. Os tendões lesados foram distribuídos aleatoriamente em dois grupos: os do GT foram tratados, e os do GC usados como controle. Ao $12^{\circ}$ dia do experimento, os equinos do GT receberam o implante das células da fração mononuclear. Os animais foram submetidos ao esquema de atividade física crescente após a indução da lesão, composta por caminhadas diárias, como apresentado a seguir: do $15^{\circ}$ ao $45^{\circ}$ dia, andar ao passo, por 15 minutos, uma vez ao dia; do $46^{\circ}$ ao $60^{\circ}$ dia, andar ao passo, por 15 minutos, duas vezes ao dia; do $61^{\circ}$ ao $90^{\circ}$ dia, andar ao passo, por 30 minutos, uma vez ao dia; do $91^{\circ}$ ao $120^{\circ}$ dia, andar ao passo, por 30 minutos, duas vezes ao dia. Aos 120 dias, todos os membros anteriores foram submetidos à biópsia de fragmento dos tendões flexores digitais superficiais.

Para a coleta de sangue da medula óssea, realizaram-se sedação e bloqueio anestésico local em região das esternebras e introdução de agulha Komiyashiki $11 \mathrm{G}$, no interior da medula óssea da quinta esternebra. Com auxílio de uma seringa de $20 \mathrm{~mL}$ contendo $1 \mathrm{~mL}$ de heparina, coletou-se o material. O volume total coletado foi, em média, de $15-20 \mathrm{~mL}$ de sangue. $O$ sangue foi imediatamente homogeneizado, acondicionado em caixa térmica e encaminhado ao Departamento de Genética e Citogenética Animal.

O sangue foi inicialmente filtrado em equipo de transfusão, lavado com solução salina tamponada com fosfato Dulbecco's PBS (DPBS) e depositado em Histopaque $(\mathrm{d}=1,0770)$. Os tubos foram centrifugados para separação dos constituintes do sangue por gradiente de densidade. Após a centrifugação, formou-se um halo esbranquiçado no meio do tudo contendo as células mononucleares, o qual foi separado e lavado com DPBS. Seguiu-se à contagem das células e ao teste de viabilidade celular por exclusão do azul de tripan $0,2 \%$. Para o implante, o material foi ressuspenso em $0,5 \mathrm{~mL}$ de soro autólogo recém-coletado. Os membros que compunham o GT receberam injeção 
intratendínea de células mononucleares de medula óssea, e os membros do GC receberam injeção de $0,5 \mathrm{~mL}$ de solução salina $0,9 \%$.

Os animais foram acompanhados por meio de exames físicos e ultrassonográficos desde o dia 0 até $\mathrm{o} 120^{\circ}$ dia, quando foi realizada biópsia tendínea para verificação das características histológicas e imunoistoquímicas. As características avaliadas ao exame físico foram grau de claudicação - escores de 0 a 5 -, presença de sensibilidade e aumento de volume. Procedeu-se, ainda, ao exame ultrassonográfico dos animais nos dias 12 - momento 1 (M1), momento 30 (M2), momento 60 (M3), momento 90 (M4) e momento 120 (M5) -, para que fossem avaliados o tamanho do tendão e da lesão, o percentual da área lesada no interior do tendão, o alinhamento de fibras e a ecogenicidade, graduada de 0 a 4 , da seguinte forma: 0 - padrão normal (ecoico); 1 - queda de $25 \%$ do padrão ecoico (predominantemente ecoico); 2 - queda de $50 \%$ do padrão ecoico; 3 queda de $75 \%$ do padrão ecoico (predominantemente anecoico); 4 - queda de $100 \%$ do padrão ecoico (totalmente anecoico).

Uma nova coleta foi feita um mês após o implante, para que fossem realizados o cultivo e a marcação celular com CD34 e CD45, confirmando a presença de células mesenquimais na amostra. Para tanto, após a separação da fração mononuclear, esta foi posta em garrafas de cultura e cultivadas por 10 a 15 dias até atingirem confluência $80 \%$. Após este período, as células presentes foram marcadas com anticorpos CD34 e CD45, conforme instruções do fabricante, e analisadas em citômetro de fluxo.

Para a avaliação das alterações histológicas da reparação dos tendões lesados, foram considerados: quantidade e características dos fibroblastos, presença de neovascularização, presença de fibras colágenas, aparência da matriz extracelular e seu arranjo, e, também, o grau de organização tecidual. Para determinação da expressão dos colágenos, foi mensurado o percentual de células marcadas, com auxílio do programa Leica QWin, por meio do processador de imagens binárias.

Para as variáveis não paramétricas, recorreu-se aos testes de Friedman e de Wilcoxon para amostras pareadas. Para as variáveis quantitativas contínuas, utilizou-se a metodologia de análise de variância para medidas repetidas.

\section{RESULTADOS E DISCUSSÃO}

A realização de biópsia tendínea permitiu a avaliação histopatológica, observando-se a organização tecidual, e imuoistoquímica, com a caracterização das fibras colágenas tipo I presentes no tendão sadio - e tipo III - presentes no tecido cicatricial.

O número médio de células obtidas, a viabilidade e o número de células viáveis totais foram, respectivamente, $42,92 \times 10^{6}, 85,5 \%$ e $36,7 \times$ $10^{6}$. O teste de viabilidade celular antes do implante celular, semelhante ao realizado por Perin et al. (2004), resultou em $96 \%$ de viabilidade, e o de Barreira (2008) 76\%.

O uso da fração mononuclear no tratamento de lesões ortopédicas em equinos tem a vantagem de poder ser realizada no momento do diagnóstico, com menor tempo de preparo das células e custos, no entanto esta é uma mistura heterogênea de tipos celulares (Richardson et al., 2007). O cultivo das células provenientes da fração mononuclear confirmou a existência de células mesenquimais, caracterizado pela capacidade de crescimento celular e sua aderência ao plástico. As células cultivadas apresentaram $12 \%$ de marcação para CD34 e $78 \%$ para CD45, ambos em primeira passagem.

A hipoecogenicidade da lesão no exame ultrassonográfico auxiliou a sua visualização, facilitando a realização do implante em seu exato local. Ocorreu mudança na ecogenicidade da lesão logo após o momento do implante celular, o que se deve à maior ecogenicidade produzida pela alta concentração celular, que, a curto prazo, pode ser considerada erroneamente uma melhora da lesão.

Todas as características avaliadas ao exame físico avaliado mostraram melhora gradativa por todo o período. A claudicação e o aumento de temperatura local foram as primeiras características a regredir completamente ao primeiro mês, ao contrário do aumento de volume, que permaneceu leve até o momento da biópsia, em quatro animais. $\mathrm{O}$ grau de 
claudicação foi variável a partir, em média, do grau 2, em ambos os grupos.

Quanto à atividade locomotora após a administração de colagenase, observou-se claudicação moderada, que não estava mais presente aos 35 dias. Estes dados assemelham-se aos de Foland et al. (1992), que relataram aparecimento imediato de claudicação moderada após aplicação de colagenase, e aos de Marxen et al. (2004), que observaram, após 24 horas da lesão, claudicação entre 2 e 3 , que se reduziu gradualmente até os 45 dias. A claudicação em grau moderado é um dos primeiros sinais a serem observados na clínica, quando o desenvolvimento da tendinite é resultante de esforço devido ao exercício, seguido de ruptura de fibras, o que, de forma similar, ocorre na indução da tendinite com o uso de colagenase. Esta claudicação inicia-se em grau moderado, torna-se leve em alguns dias e discreta ao redor de 30 dias, seja na clínica ou na tendinite experimental.

O maior valor da lesão e sua maior porcentagem de comprometimento das fibras foram observados aos 30 dias (M2), reduzindo-se gradualmente com o passar do tempo. Apesar de a área da lesão do grupo-tratado ter se iniciado com valor maior que o do grupo-controle, este quadro inverteu-se no decorrer da pesquisa. A porcentagem de comprometimento de fibras, calculada pela relação entre a área lesada e a área total do tendão, revelou-se semelhante à situação apresentada pela área da lesão. Ambas atingiram o seu maior valor aos 30 dias, sendo os valores do grupo-tratado maior que os do grupo-controle, ocorrendo inversão do quadro aos 60 dias, com maior valor no grupo-controle. A porcentagem de área lesada média foi significativamente menor ao $120^{\circ}$ dia do que ao $12^{\circ}(\mathrm{P}=0,0003)$ e ao $30^{\circ}$ dias $(\mathrm{P}<0,0001)$, em ambos os grupos. Ainda, a média da ecogenicidade da lesão inicial foi a mesma em ambos os grupos, com seu maior valor aos 30 dias. Para o GT ocorreu mudança significativa do escore de ecogenicidade ao longo do tempo $(\mathrm{P}<0,001)$, assim como para GC $(\mathrm{P}=0,003)$, e não houve diferença significativa entre os dois grupos, em todas as avaliações $(\mathrm{P}>0,05)$. A lesão tendínea continuou a se desenvolver até, aproximadamente, 21 dias em razão da ação da colagenase ou mesmo do edema produzido, que comprimia as células sadias ao seu redor, causando a morte celular de tenócitos.
Este maior valor da lesão ocorreu até os 30 dias. $\mathrm{O}$ valor da ecogenicidade ao exame ultrassonográfico confirma esta continuidade de desenvolvimento da lesão até M2.

Outro dado importante foi a porcentagem de redução do tamanho da lesão em relação à sua maior área (30 dias) nos diferentes momentos consecutivos, de forma a comparar a sua real progressão. Tanto em GT quanto em GC a porcentagem de redução da lesão aumentou à medida que a avaliação se afastou do $30^{\circ}$ dia, e, adicionalmente, houve uma diferença significativa $(\mathrm{P}=0,0143)$ entre $\mathrm{o}$ percentual de redução da lesão dos grupos tratado e controle, sempre maior no grupo tratado (Fig. 1). Isso comprova a eficiência das células mononucleares como tratamento de lesões tendíneas em equinos, com seu melhor preenchimento.

Os resultados do exame ultrassonográfico demonstraram que os 120 dias de acompanhamento não foram suficientes para que as lesões atingissem a normalidade do padrão ecoico. Os valores de comprometimento das fibras foram, em média, de $40 \%$ no grupo-tratado e de $33 \%$ no grupo-controle. Este achado assemelha-se ao observado por Sutter (2007), que descreveu um aumento da área lesada aos 30 dias após a lesão, como resposta ao trauma. De maneira semelhante, lesões induzidas pela aplicação de colagenase foram mais severas ao redor dos 20 dias, conforme descrito por Marxen et al. (2004). Aos 120 dias, houve redução da porcentagem de área lesada, atingindo valores de $16 \%$ no grupo tratado e $11 \%$ no grupo-controle, não sendo este um período suficiente para a completa cicatrização da lesão, resultado semelhante ao obtido por Alves et al. (2001). O valor da ecogenicidade máxima após a indução da lesão foi grau 3,5 para os grupos tratado e controle. Lesões obtidas no presente experimento foram mais severas quanto à ecogenicidade do que as observadas por Barreira et al. (2008), as quais obtiveram lesões de ecogenicidade grau 2,5. Aos 120 dias, a ecogenicidade apresentada foi grau 1 no GT e 1,3 em GC, mostrando que este tempo não foi suficiente para a normalização da ecogenicidade. Resultados descritos por Alves et al. (2001), aos 120 dias após a lesão, mostraram que o grau de ecogenicidade variou de 1 a 2, semelhante aos também observados por Marxen et al. (2004), aos 150 dias pós-lesão. 
Perfis Médios

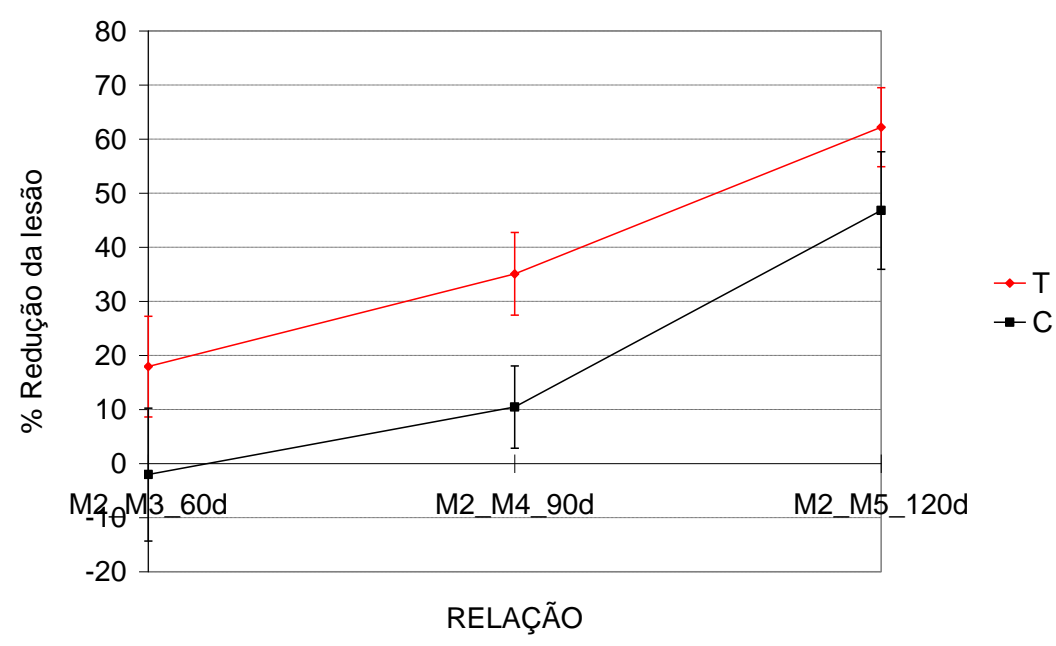

Figura 1. Equino. Perfis médios da porcentagem (\%) de redução da lesão ao longo das avaliações dos grupos tratado (linha vermelha) e controle (linha preta).

Os resultados obtidos na avaliação histológica realizada ao $120^{\circ}$ dia após a indução da lesão mostraram que todos os animais apresentavam fibroplasia, de maneira semelhante aos relatos existentes na literatura (Goodship et al., 1994). Marxen et al. (2004) descreveram que, independentemente do tratamento aplicado à lesão tendínea, foram observados graus intensos de vascularização aos 150 dias, com grande número de vasos reciduais e recém-formados por todo fragmento tendíneo.

Silver et al. (1983) descreveram hipercelularidade aos 14 meses após a indução experimental da lesão tendínea, observando o alinhamento de fibras, porém ainda com anormalidades histológicas. Os fibroblastos nos equinos do grupo-tratado, ainda com alta celularidade, apresentaram núcleos mais alongados e coloração da matriz mais forte que nos do grupo-controle. No GT foram observadas fibras colágenas com maior organização e alinhamento, porém ainda não semelhante ao tecido sadio. Os núcleos do fibroblastos encontravam-se alongados, todavia a celularidade ainda foi alta se comparada à celularidade encontrada no tendão normal, em ambos os grupos. Os animais do GC apresentaram fibroblastos com núcleos mais arredondados e fibras com menor organização (Fig. 2).
Quanto à presença de neovascularização, os equinos do GC apresentaram maior quantidade de pequenos vasos, sendo estes de parede mais espessa. Os vasos não foram identificados em grande número na maioria dos cortes histológicos, diferentemente do que foi identificado por Silver et al. (1983), e em equinos tratados com glicosaminoglicanos polissulfatados, quando foi descrita uma vascularização em grande intensidade (Marxen $e t$ al., 2004). Marr et al. (1993) relataram que a diminuição da celularidade e da vascularização são indicativas de progressiva maturação do tecido de granulação, pois a deposição de colágeno exerce pressão mecânica sobre as delicadas paredes de capilares neoformados, levando à diminuição da vascularização.

O efeito do tratamento com células da fração mononuclear de medula óssea, em especial das células precursoras mesenquimais, aplicadas às lesões tendíneas induzidas neste experimento, possibilitou melhor reparo tendíneo sob aspectos histológicos. Esta consideração está de acordo com dados divulgados por Herthel (2001), porém em resultados baseados nas análises clínica, ultrassonográfica e funcional das estruturas tendoligamentares. Barreira et al. (2008), ao avaliarem histologicamente lesões tratadas com células-tronco mesenquimas contidas na fração mononuclear 48 dias após a sua indução, 
constataram redução da inflamação neste período.

O protocolo de exercícios adotado promoveu estresse longitudinal das fibras tendíneas, sendo observada melhora na organização tecidual em ambos os grupos, concordando com um período mínimo de 90 dias para avaliação da cicatrização, conforme descreveram Goodship (1994) e Alves et al. (2001).

Para que se institua um tratamento com células mononucleares ou mesmo com células-tronco, é necessário que se forme um tecido de granulação de suporte, que promova a adesão das células injetadas sem que haja fibrose substancial (Smith, 2004). Lesões centrais, com uma região hipoecoica, devem ser ainda visíveis, como as geralmente apresentadas nas tendinites do flexor digital superficial em equinos, e se preencherem rapidamente, no momento do implante (Fortier e Smith, 2008).

$\mathrm{Na}$ avaliação imunoistoquímica, o anticorpo para colágeno tipo I mostrou marcação positiva de $46,9 \%$ no grupo tratado e de $36,5 \%$ no grupocontrole. Tal diferenciação foi significativa $(\mathrm{P}=0,0313)$. Este resultado sinaliza uma quantidade maior de colágeno do tipo I presente no grupo-tratado que no grupo-controle, sendo este tipo caracterizado como a principal fibra constituinte do tendão sadio. Quanto ao colágeno tipo III, que identifica a fibra colágena existente no tecido cicatricial, este foi encontrado em $31,3 \%$ no GC e em $25,9 \%$ no GT, e esta diferença não foi significativa $(\mathrm{P}=0,312)$ (Fig. 3).

Durante o processo cicatricial, a fase proliferativa inicial é marcada por um pico na expressão de colágeno tipo III. Posteriormente, na fase de organização, a fibra colágena do tipo III é substituída por fibra colágena tipo I (Matsumoto et al., 2002). Os resultados da imunoistoquímica revelaram maior quantidade de colágeno tipo I se comparada ao tipo III, resultando em melhor cicatrização. No entanto, a quantidade de colágeno tipo III marcada ainda foi alta, representando a continuidade do processo de cicatrização. Observou-se diferença significativa na marcação para colágeno tipo I entre os grupos, maior no grupo-tratado, porém não para colágeno tipo III. Crovace et al. (2007) descreveram a presença de colágeno tipo I maduro em animais tratados com implantes de células da fração mononuclear e de células mesenquimais cultivadas, que apresentaram arquitetura tendínea normal entre 16 e 21 semanas após a indução de lesão. O grupo placebo apresentou maior quantidade de colágeno tipo III e menor organização. Hankemeier et al. (2007) também verificaram melhora na qualidade do tecido cicatricial e de sua resistência pela razão apresentada entre colágeno tipo I:colágeno tipo III, ao avaliarem lesões ligamentares em humanos. $\mathrm{Na}$ análise bioquímica de lesões tendíneas não tratadas, foi caracterizado um alto nível de colágeno tipo III em relação ao colágeno tipo I, sendo mantida a quantidade total de colágeno (Birch et al., 1997). Nesse caso, a marcação para fibras colágenas do tipo I e III foi difusa. Satomi et al. (2008) descreveram a marcação via imunofluorescência para colágeno tipo I e III na tendinose em humanos com distribuição semelhante, sendo a fibra colágena tipo I marcada de forma discreta e difusa, como também para fibra colágena tipo III, porém mais proeminente. 


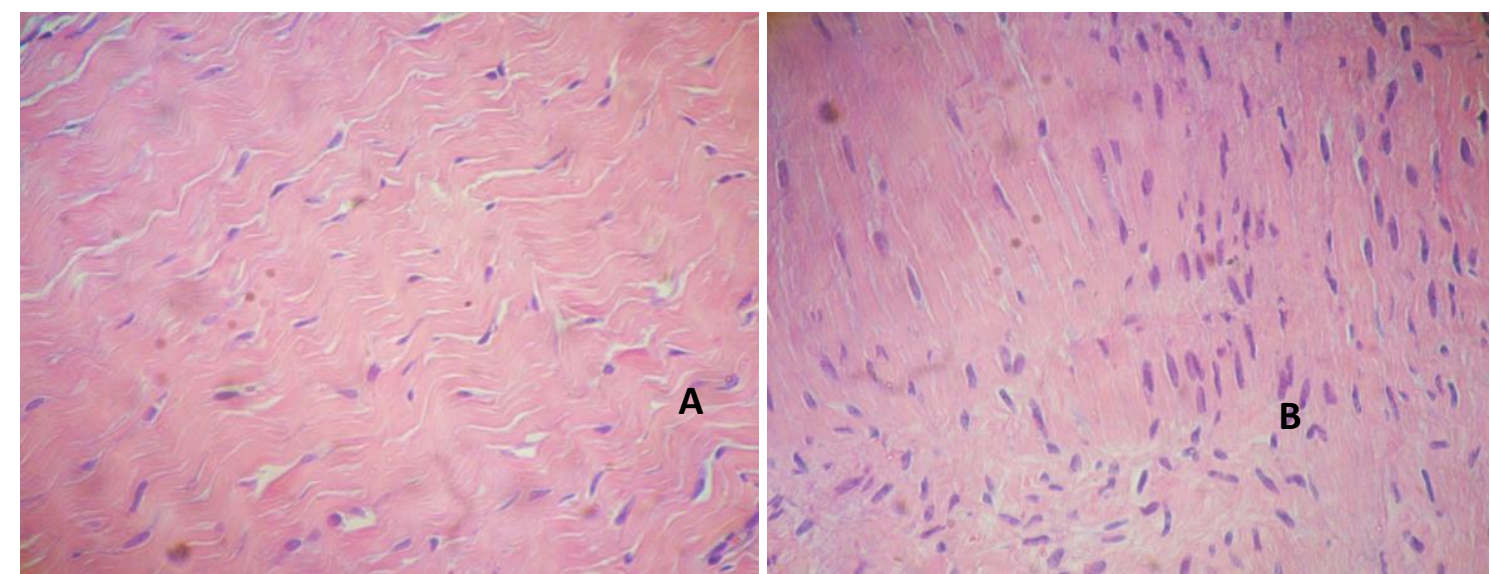

Figura 2. Equino. Cortes histológicos aos 120 dias: (A) tendão tratado apresentando núcleos alongados e ondulações das fibras. HE, obj. 40; (B) tendão do grupo-controle com núcleos mais arredondados, sem padrão de ondulações. HE, obj. 40.
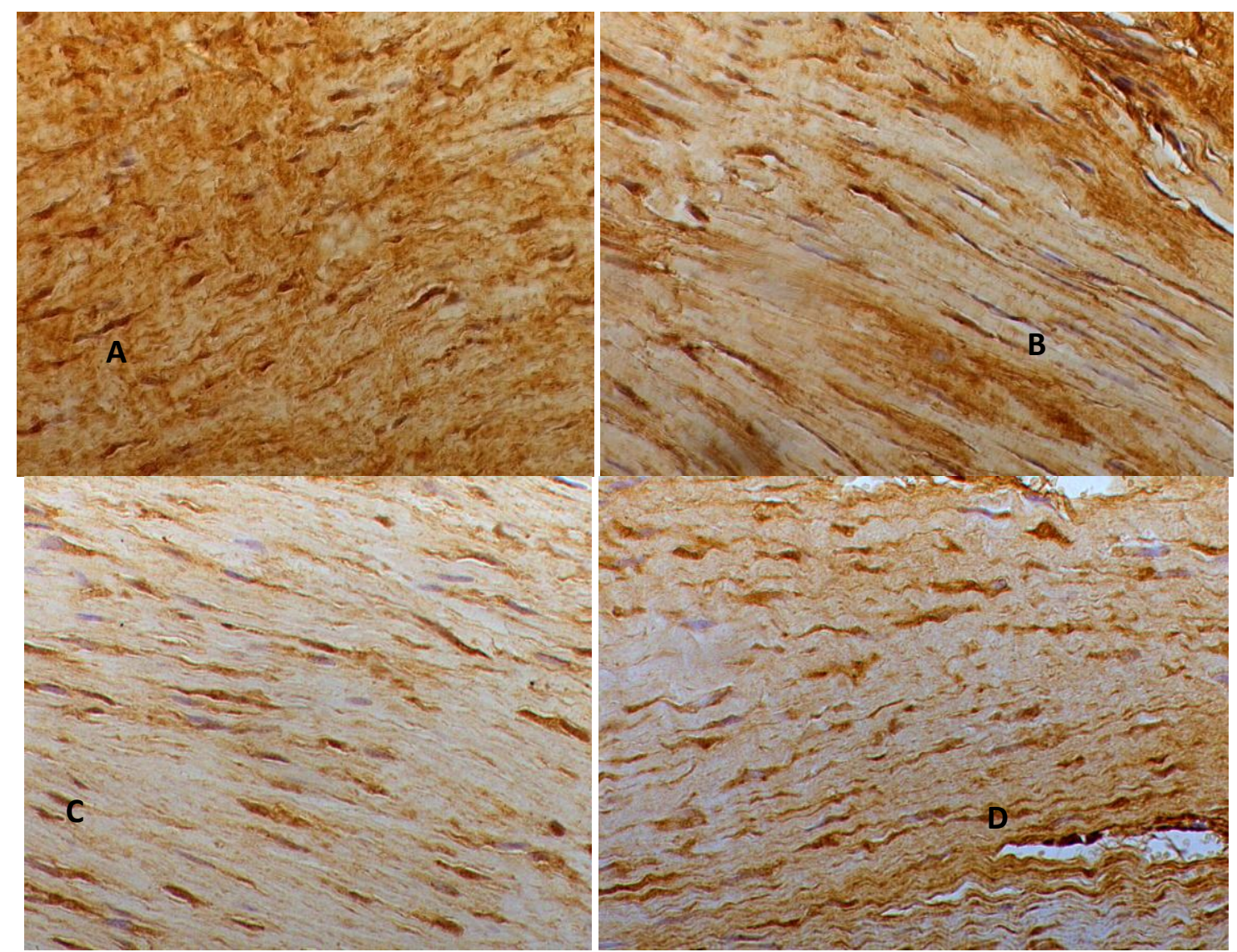

Figura 3. Imunoistoquímica do tecido tendíneo tratado e controle aos 120 dias: (A) colágeno tipo I membro tratado. Obj. 40; (B) colágeno tipo I membro controle. Obj. 40; (C) colágeno tipo III membro tratado. Obj. 40; (D) colágeno tipo III membro controle. Obj. 40. 


\section{CONCLUSÕES}

A terapia celular tendínea com células mononucleares da medula óssea melhora a organização tecidual ao promover maior alinhamento das fibras e maior percentual de redução da área lesada. O tecido neoformado é de melhor qualidade quando tratado com células mononucleares, por apresentar maior expressão de fibras colágenas tipo I aos 120 dias de tratamento.

\section{AGRADECIMENTOS}

À Fundação de Amparo à Pesquisa do Estado de São Paulo (FAPESP), pela concessão de bolsa de mestrado.

\section{REFERÊNCIAS BIBLIOGRÁFICAS}

ALVES, A.L.G.; RODRIGUES, M.A.M.; AGUIAR, A.J.A. et al. Effects of the betaaminopropionitrile fumarate and exercise on equine tendon healing: gross and histological aspects. $J$. Equine Vet. Sci., v. 21, p.335-340, 2001.

BARREIRA, A.P.B.; ALVES, A.L.G.; SAITO, M.E. et al. Autologous Implant of Bone Marrow Mononuclear Cells as Treatment of Induced Equine Tendinitis. Intern. J. Appl. Res. Vet. Med., v.6, p.4654,2008

BIRCH, H.L.; WILSON, A.M.; GOODSHIP, A.E. The effect of exercise-induced localised hyperthermia on tendon cell survival. J. Exp. Biol., v.1, p.17031708,1997

CROVACE, A.; LACITÍGNOLA, L.; DE SIENA, R. et al. Cell therapy for tendon repair in horses: an experimental study. Vet. Res. Commun., v.31, p.281283, 2007.

FOLAND, J.W.; TROTTER, G.W.; POWERS, B.E. et al. Effect of sodium hyaluronate in collagenase induced superficial digital flexor tendinitis in horses. Am. J. Vet. Res., v. 53, p.2371-2376, 1992.

FORTIER, L.A.; SMITH, R.K. Regenerative medicine for tendinous and ligamentous injuries of sport horses. Vet. Clin. N. Am.: Equine Pract., v.24, p.191-201, 2008.

GOODSHIP, A.E.; BIRCH, H.L.; WILSON, A.M. The pathobiology and repair of tendon and ligament injury. Vet. Clin. N. Am.: Equine Pract., v.10, p.323349, 1994.
HANKEMEIER, S.; VAN GRIENSVEN, M.; EZECHIELI, M. et al. Tissue engineering of ligaments by human bone marrow stromal cells in a liquid fibrin matrix: histological, biomechanical, and molecular biological results of a study with immunodeficient rats. Arch. Orthopaed. Trauma Surg., v.127, p.815-821, 2007.

HERTHEL, D.J. Enhanced suspensory ligament healing in 100 horses by stem cells and other bone marrow components. In: AMERICAN ASSOCIATION OF EQUINE PRACTITIONERS, 47., 2001, San Diego. Proceedings... San Diego, 2001. p.319-321.

MARR, C.M.; McMILLIAN, I.; BOYD, J.S. et al. Ultrasonography and histopathological findings in equine superficial digital flexor tendon injury. Equine Vet. J., v.25, p.23-29, 1993.

MARXEN, S.; NETO, J.C.L.; CANOLA, J.C. et al. Polissulfato de glicosaminoglicanas no tratamento intralesional de tendinite induzida em equinos: avaliação clínica, ultrassonográfica e histopatológica. Arq. Bras. Med. Vet. Zootec., v.56, p.701-708, 2004.

MATSUMOTO, F.; TRUDEL, G.; UHTHOFF, H. High collagen type I and low collagen type III levels in knee joint contracture. Acta Orthop. Scand., v.73, p.335-343, 2002.

PERIN, E.C.; DOHMANN, H.F.; BOROJEVIC, R. et al. Improved exercise capacity and ischemia 6 and 12 months after transendocardial injection of autologous bone marrow mononuclear cells for ischemiccardiomyopathy. Circulation, v.110, p.213218, 2004

RICHARDSON, L.E.; DUDHUA, J.; CLEGG, P.D. et al. Stem cells in veterinary medicine- attempts at regenerating equine tendon after injury. Trends Biotechnol., v.25, p.409-416, 2007.

SATOMI, E.; TEODORO, W.R.; PARRA, E.R. et al. Changes in histoanatomical distribution of types I, III and $\mathrm{V}$ collagen promote adaptative remodeling in posterior tibial tendon rupture. Clinics, v.63, p.9-14, 2008.

SILVER, I.A.; BROWN, P.N.; GOODSHIP, A.E. et al. A clinical and experimental study of tendon injury, healing and treatment in the horse. Equine Vet. J. Suppl., v.1, p. 1-43, 1983.

SMITH, R.K.W. Stem cell therapy for tendon and ligament injuries - clinical results. In: EUROPEAN SOCIETY OF VETERINARY ORTHOPAEDICS AND TRAUMATHOLOGY CONGRESS, 12., 2004, Munique. Proceedings...Munique, 2004. p.187-188.

SUTTER, W.W. Autologous cell-based therapy for tendon and ligament injuries. Clin. Tech. Equine Pract., v.6, p.198-208, 2007. 